\title{
Contact grouting taken into account when calculating arched frame supports
}

\author{
Alexander Liskovets $^{1}$, Victor Tatsienko ${ }^{1, *}$, Vyacheslav Gogolin ${ }^{1}$ \\ ${ }^{1}$ T.F. Gorbachev Kuzbass State Technical University, 28, Vesennyaya street, Kemerovo, 650000, \\ Russian Federation
}

\begin{abstract}
One of the current trends in the technology of supporting capital and preparatory workings is the use of contact grouting. The contact grouting is designed to increase the bearing capacity of the frame supports. The paper considers a method for calculating the support pressure and the displacement of the support crown. The calculation method is based on the interaction of the system of blocks "support - filling layer - broken rock layer - undisturbed rock". The following factors were taken into account in the method of calculating the frame arch support: depth of the roadway development, mine working cross-section, the support section, the width of the filling layer and its deformation characteristics, as well as the deformation and strength characteristics of the rock mass. Checking of the support strength state is done by comparing the calculated load versus the rated bearing capacity of the support. The developed technique allows making the choice of support in various mining conditions of the application.
\end{abstract}

\section{Introduction}

The intensification of mining operations at the underground mines of JSC SUEK-Kuzbass requires timely development of replacement production faces as well as ensuring the fire protection of the workings driven in coal, and the stability of the workings driven in difficult geological conditions. The methods used for driving and supporting the workings create gaps in the space behind the support 0.2 to $0.3 \mathrm{~m}$ wide. At the same time, the sides of the workings have destruction zones, which make it difficult to support the workings and increase the time of equipment installation and dismantling $[1,2]$.

Measures of rock consolidation around the workings by injection of cement mortars or resins in them present an effective way to increase the rock stability, reduce displacements and loads on the support, and, therefore, provide the possibility of using lighter support and increase the pace of mine construction [3]. In addition, the creation of an insulating layer between the coal mass and the support increases the fire resistance of the workings.

The application of such technology is difficult, in particular, due to the lack of an available methodology for calculating the parameters of the frame support with the contact grouting.

The existing calculation method is described in the "Instructions for the selection of

* Corresponding author: ipeb@kuzstu.ru 
frame pliable supports of mine workings" [4] approved in 1991 and recommended in [5, 6, 7].

The procedure for selecting section dimensions and calculating support parameters for a particular mine working is as follows:

a) the dimensions of the calculated finished section of a working are chosen, taking into account the requirements for various conditions;

b) the dimensions of the rock section are determined approximately, taking into account the support thickness and pliability and the thickness of the filling material;

c) the expected rock displacements are calculated differentially in the roof, side walls and floor of the working, taking into account the mining factors;

d) in accordance with the maximum displacements of the rock along the boundaries of the working, the standard and calculated loads on the support are determined, its type and design are chosen, and the installation density is calculated taking into account the support resistance.

\section{Materials and Methods}

According to the Code of Rules for "Underground Mines" [6], the displacements compensated by compression of the filling material depend on the compressibility of the material, the thickness of the filling layer and the calculated load on the support and are determined empirically. For the filling material from crushed rocks in the absence of experimental data, it is allowed to take equal to $25 \%$ of the thickness of the filling layer.

Thus, the existing calculation technique is based on the use of a significant number of correction factors, nomograms, and experimental data in order to take into account specific mining and geological conditions.

Experimental studies of the load-bearing capacity of the support with the use of contact grouting are given in many works and show its effectiveness [8-12] compared to the backfill. However, these observations were carried out in specific mining and geological conditions and certain characteristics of the grouting mortar. And this does not allow the authors to extend their conclusions to wider conditions.

As the review of foreign literature showed, it focuses on goaf stowing, reduction of stresses and movements from previously worked out seams [13, 14]. This experience is not applicable when calculating the pressure on the support with the contact grouting.

Therefore, the development of a modern methodology for calculating the parameters of the support with contact grouting is an urgent task.

The authors developed a methodology for support calculation, taking into account the interaction of blocks "support - filling layer - broken rock layer - undisturbed rock strata". The design scheme is shown in the figure 1. 


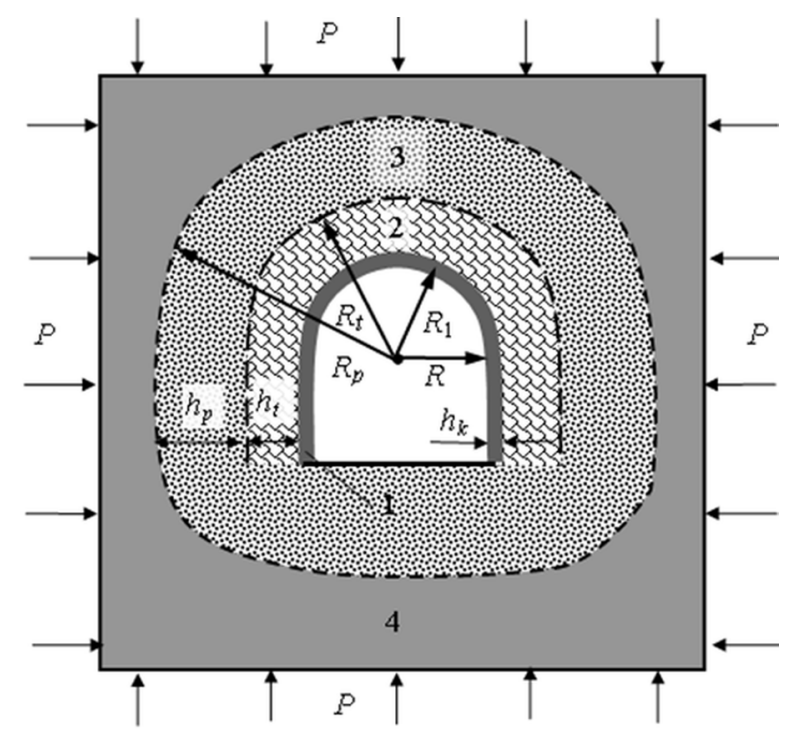

Fig. 1. The design scheme: 1 - support; 2 - filling layer; 3 - partially broken rock; 4 - enclosing rock strata.

\section{Sample of Calculation}

The roadway is driven at the depth $H, \mathrm{~m}$. The roadway doesn't get into the zone of increased rock pressure, the initial rock pressure is $p=\gamma H=0,025 \cdot H, \mathrm{MPa}$.

The roadway cross-section is $S, \mathrm{~m}^{2}$. The reduced radius of the roadway is $R=\sqrt{5 / \pi}, \mathrm{m}$.

AKP support with section SVP-17 $\div 33$ of the equivalent height $h_{k}, \mathrm{~m}$, which value is selected from Table 1.

Table 1. Equivalent support cross-sectional dimensions for various SVP sections [15]

\begin{tabular}{|c|c|c|c|c|}
\hline $\begin{array}{c}\text { Hot-rolled section for } \\
\text { mine timbering } \\
\text { SVP }\end{array}$ & $\begin{array}{c}\text { Cross-section } \\
\text { area } \boldsymbol{S}^{\boldsymbol{*}}, \mathbf{c m}^{\mathbf{2}}\end{array}$ & $\begin{array}{c}\text { Inertia } \\
\text { moment } \boldsymbol{I}^{\mathbf{*}}, \\
\mathbf{c m}^{\mathbf{4}}\end{array}$ & $\begin{array}{c}\text { Equivalent } \\
\text { height } \boldsymbol{h}_{\boldsymbol{k}}, \mathbf{c m}\end{array}$ & $\begin{array}{c}\text { Equivalent } \\
\text { width } \boldsymbol{b}, \mathbf{c m}\end{array}$ \\
\hline 17 & 21.73 & 243.4 & 11.59 & 1.87 \\
\hline 19 & 24.44 & 322.8 & 12.59 & 2.22 \\
\hline 22 & 27.91 & 428.6 & 13.57 & 2.06 \\
\hline 27 & 34.37 & 646.1 & 15.02 & 2.29 \\
\hline 33 & 42.53 & 999.5 & 16.79 & 2.53 \\
\hline
\end{tabular}

Young's modulus of the support $E_{k}=(2 \div 4) \cdot 10^{3} \mathrm{MPa}$.

For rock strata: Young's modulus E, Poisson's ratio $v$, compression strength $\sigma_{\mathrm{s}}$ and structural weakness factor $k_{\mathrm{c}}$ are determined for specific mining conditions.

The filling layer is formed using concrete B-15, 25 with Young's modulus $E_{t}$,

When calculating for short-term loads, the elastic modulus of concrete $E_{t}$ should be multiplied by a factor of 0.85 ,

When calculating for long-term loads:

- for columns and walls - by a factor of 0.6 ;

- for plates (without cracks) - by a factor of 0.3 ;

- for plates (with cracks) - by a factor of 0.2 .

The width of the filling layer is ht, $\mathrm{m}$ 
The radius of the mine working with support is $R_{1}=R+h_{k}$.

The radius of the mine working with the filling layer is $R_{t}=R_{1}+h_{t}$.

The parameters that determine the pressure on the support and the displacement of the support crown are calculated successively:

1) $c=\frac{1-v}{v}-$ factor determining the maximum circumferential stress;

2) $k=\frac{2 c P+k_{c} \cdot \sigma_{s} /(1+v)}{2 P-k_{c} \cdot \sigma_{s} /(1+v)}-$ dimensionless factor determining the distribution of stresses in the zone of broken rock;

3) $\sigma_{m}=\frac{2 c P+k_{c} \cdot \sigma_{S} /(1+v)}{c+1}-$ maximum circumferential stress of enclosing rock;

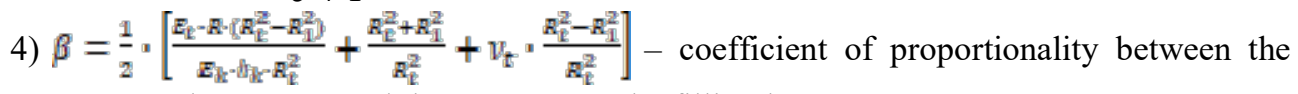
pressure on the support and the pressure on the filling layer;

5) $\alpha=\frac{\beta^{2} \cdot R_{i}^{2}+R_{i}^{2}-2 \cdot \beta \cdot R_{i}^{2}}{R_{q}^{2}-R_{i}^{2}}-v_{t} * \beta^{2}-$ factor determining pressure on the support.

The pressure on the support is calculated by the formula

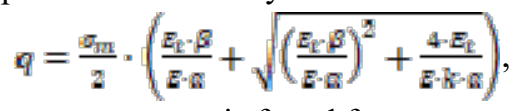

The displacement of the support crown is found from

$$
u=\frac{1}{E_{k 2}} \cdot \frac{q_{R} \cdot R^{2}}{E_{k 2}} \text {. }
$$

The found pressure $q$ makes it possible to calculate the load on the support:

where $q$-pressure on the support, $\mathrm{Pa}$;

$$
P_{k}=q \cdot b \cdot L=q \cdot b \cdot 1,5 \pi \cdot \sqrt{S / \pi},
$$

$b$ - equivalent width of the support cross-section, m (see Table 1); $L$ - the total length of support props and crown, $L=\frac{3}{4} \cdot 2 \pi R=1,5 \pi R$, m;

$R$ - reduced radius of support, $R=\sqrt{S / \pi}, \mathrm{m} ; S$ - roadway cross-section, $\mathrm{m}^{2}$.

The calculated load on the support $P_{k}$ is compared with the support bearing capacity $N_{s}$ [2] which is 300,330 and $370 \mathrm{kN} /$ frame for sections SVP-22, SVP-27 and SVP-33, respectively.

If $P_{k}<N_{s}$, then the support retains its strength condition.

The radius of the zone of broken rock

$$
R_{p}=R_{t}=\left(\frac{2 p}{(k+1) p t}\right)^{\frac{1}{k-1}}
$$

where $R_{t}$ - radius of the mine working with a filling layer, $R_{t}=R+h_{k}+h_{t}$;

$p_{t}-$ pressure on the filling layer from the support side, $p_{t}=\beta \cdot q$.

The width of the fractured zone is $h_{p}=R_{p}-R_{t}$.

The mine working is driven at a depth of $H=200 \mathrm{~m}$. The working does not fall within the zone of high rock pressure, the initial rock pressure is $p=\gamma H=0.025-200=5 \mathrm{MPa}$. The cross-sectional area of the working is $S=20 \mathrm{~m}^{2}$. The reduced radius of the working $R=\sqrt{20 / \pi}=2,52 \mathrm{~m}$. The AKP support is used with SVP-27 section and equivalent height $h_{k}=0.15 \mathrm{~m}$, the Young's modulus for the support $E_{k}=2 \cdot 10^{3} \mathrm{MPa}$.

The rock strata is represented by mudstones with Young's modulus of $E=10^{4} \mathrm{MPa}$, lateral deformation factor of $\mathrm{v}=0.25$, compressive strength of $\sigma_{S}=10 \mathrm{MPa}$, and a structural weakening factor of $k_{c}=0,6$.

The filling layer is formed using concrete with a Young's modulus $E_{\mathrm{t}}=20 \mathrm{MPa}$. The width of the filling layer is $h_{t}=0.2 \mathrm{~m}$.

The radius of the mine working with the support is $R_{1}=2.52+0.15=2.67 \mathrm{~m}$. 
The radius of the mine working with the filling layer is $R_{t}=2.67+0.2=2.87 \mathrm{~m}$.

The parameters that determine the pressure on the support and the displacement of the crown are calculated successively:

1) $r=\frac{1-V}{v}=\frac{1-0,25}{0.25}=3$;

2) $k=\frac{2 c P+k_{c} \cdot \sigma_{S} /(1+v)}{2 P-k_{c} \cdot \sigma_{S} /(1+v)}=\frac{2 \cdot 3 \cdot 5+0,6 \cdot 10 /(1+0,25)}{2 \cdot 5-0,6 \cdot 10 /(1+0,25)}=6,69$;

3) $\sigma_{m}=\frac{2 c P+k_{c} \cdot \sigma_{S} /(1+v)}{c+1}=\frac{2 \cdot 3 \cdot 5+0,6 \cdot 10 /(1+0,25)}{3+1}=8,7 \mathrm{MPa}$;

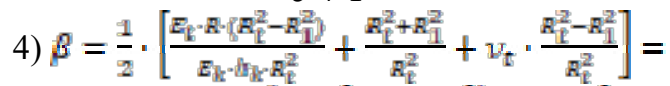

$=\frac{1}{2} \cdot\left[\frac{20 \cdot 2,52 \cdot\left(2,87^{2}-2,67^{2}\right)}{2 \cdot 10^{2} \cdot 0,15 \cdot 2,87^{2}}+\frac{2,87^{2}+2,67^{2}}{2,87^{2}}+0,25 \cdot \frac{2,87^{2}-2,67^{2}}{2,87^{2}}\right]=0,9616$;

5) $\alpha=\frac{\beta^{2} \cdot\left(R_{t}^{2}+R_{1}^{2}\right)-2 \cdot \beta \cdot R_{1}^{2}}{R_{\%}^{2}-R_{1}^{2}}-v_{t} \cdot \beta^{2}=$

$=\frac{0,9616^{2} \cdot\left(2,87^{2}+2,67^{2}\right)-2 \cdot 0,9616 \cdot 2,67^{2}}{2,87^{2}-2,67^{2}}-0,25 \cdot 0,9616^{2}=0,2195$.

We calculate the pressure on the support:

$$
\begin{gathered}
q=\frac{\sigma_{m}}{2} \cdot\left(\frac{E_{\mathrm{t}} \cdot \beta}{E \cdot \alpha}+\sqrt{\left(\frac{E_{\mathrm{t}} \cdot \beta}{E \cdot \alpha}\right)^{2}+\frac{4 \cdot E_{\mathrm{t}}}{E \cdot k \cdot \alpha}}\right)= \\
=\frac{8,7}{2} \cdot\left(\frac{20 \cdot 0,9616}{10^{4} \cdot 0,2195}+\sqrt{\left(\frac{20 \cdot 0,9616}{10^{4} \cdot 0,2195}\right)^{2}+\frac{4 \cdot 20}{10^{4} \cdot 6,69 \cdot 0,2195}}\right)=0,3614
\end{gathered}
$$

MPa.

We find the support crown displacement:

$u=\frac{1}{E_{k}} \cdot \frac{\mathrm{q}^{2} R^{2}}{\mathbb{4}_{\mathrm{k}}}=\frac{1}{2 \cdot 10^{3}} \cdot \frac{0,3614 \cdot 2,52}{0,15}=0,0082 \mathrm{~m}$.

Now, we check the support strength state.

We calculate the load on the support:

$$
P_{k}=q \cdot b \cdot 1,5 \pi \cdot R=0,3614 \cdot 10^{6} \cdot 0,02 \cdot 1,5 \cdot 3,14 \cdot 2,52=86 \mathrm{kPa} / \text { frame. }
$$

The bearing capacity of the support $N_{s}$ is $330 \mathrm{kN} /$ frame for SVP-27 section.

Since $P_{k}<N_{s}$, the support retains the strength state.

The calculation method also allows one to find the width of the zone of broken rock.

Let us find the radius of the zone of broken rock:

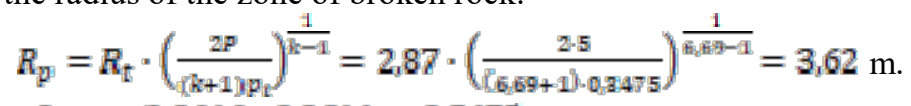

Where $p_{t}=\beta \cdot q=0,9616 \cdot 0,3614=0,3475 \mathrm{MPa}$.

Now we find the width of the fractured zone:

$$
h_{p}=R_{p}-R_{t}=3,62-2,87=0,75 \mathrm{~m} \text {. }
$$

\section{Conclusions}

1. An engineering methodology has been developed for calculating the pressure on the support and the displacement of the upper crown during contact grouting, taking into account the interaction of the blocks "support - filling layer - layer of broken rocks - 
undisturbed rock strata".

2. The initial data for the calculation are:

- depth of the working development and its area;

- modulus of support linear deformations and section number;

- modulus of linear and transverse deformations, the structural weakening factor, compressive strength of the enclosing rock;

- modulus of linear deformations and the width of the filling layer.

3. The results of the calculation are: displacement of the support crown, pressure and load on the support, the width of the zone of broken rock.

4. Checking of the support strength state is performed by comparing the calculated load and the bearing capacity of the support.

5. The developed technique allows making the choice of support in various mining conditions of application.

\section{References}

1. N. Pirieva, I. Ermakova, E3S Web of Conferences, 21, 01010 (2017)

2. I. Yermakova, V. Fedusov, E3S Web of Conferences, 105, 01049 (2019)

3. V.P. Tatsienko, A.S. Liskovets, M.V. Sablin, Bulletin KuzSTU, 2, 45-52 (2018) DOI: 10.26730/1999-4125-2018-2-45-52

4. Z. Jian, M. Zhong, Procedia Engineering 26, 1150-1156 (2011)

5. Z. Yang, S. Zhai, Q. Gao, M. Li, Journal of Rock Mechanics and Geotechnical Engineering, 7(215), 87-94 (2018)

6. D.N. Makshankin, A.V. Remezov, V.A. Gogolin, Vestnik KuzGTU, 3, 50-56 (2009) 